\title{
Language impairment in Alzheimer's disease and benefits of acetylcholinesterase inhibitors
}

This article was published in the following Dove Press journal:

Clinical Interventions in Aging

I August 2013

Number of times this article has been viewed

\author{
Steven H Ferris' \\ Martin Farlow ${ }^{2}$ \\ 'Alzheimer's Disease Center, \\ Comprehensive Center on Brain \\ Aging, New York University Langone \\ Medical Center, New York, NY, \\ ${ }^{2}$ Department of Neurology, Indiana \\ University School of Medicine, \\ Indianapolis, IN, USA
}

\begin{abstract}
Alzheimer's disease is characterized by progressively worsening deficits in several cognitive domains, including language. Language impairment in Alzheimer's disease primarily occurs because of decline in semantic and pragmatic levels of language processing. Given the centrality of language to cognitive function, a number of language-specific scales have been developed to assess language deficits throughout progression of the disease and to evaluate the effects of pharmacotherapy on language function. Trials of acetylcholinesterase inhibitors, used for the treatment of clinical symptoms of Alzheimer's disease, have generally focused on overall cognitive effects. However, in the current report, we review data indicating specific beneficial effects of acetylcholinesterase inhibitors on language abilities in patients with Alzheimer's disease, with a particular focus on outcomes among patients in the moderate and severe disease stages, during which communication is at risk and preservation is particularly important.

Keywords: Alzheimer's disease, donepezil, cognition, language, communication, clinical trials
\end{abstract}

\section{Introduction}

Alzheimer's disease (AD) is the most common etiology for dementia. Worldwide, it is currently estimated that 35 million people have $\mathrm{AD}$ or a related dementia, and with increasing life expectancy, global prevalence is projected to increase to around 66 million by 2030 and to more than 115 million by $2050 .{ }^{1}$ In the United States, 5.4 million individuals of all ages are currently estimated to have AD, with the vast majority $(>95 \%)$ aged older than 65 years. ${ }^{2}$ With increasing life expectancy and aging of the baby boomer generation, the elderly US population (age $\geq 65$ years) is projected to nearly double to 71 million by $2030 .^{2}$ Applying this population increase to current prevalence estimates, barring medical breakthroughs to prevent, slow, or stop the disease, 16 million elderly Americans are projected to have AD by $2050 .^{2} \mathrm{As}$ with many other diseases of the elderly, $\mathrm{AD}$ is associated with significant burden on the person with the disease, on their caregivers, and on society as a whole through the considerable cost of disease-related care. At present, annual AD-related care costs in the United States are around \$200 billion. $^{2}$

Patients with AD progress through mild, moderate, and severe stages, and more than half are expected to be at the moderate or severe stages of the disease at any given time (Figure 1). ${ }^{3,4}$ Progressive cognitive decline is the fundamental feature of AD symptomatology, ${ }^{5}$ and is characterized by episodic memory loss and impairments in attention/concentration, orientation, judgment, visuospatial abilities, executive function, and language. ${ }^{6}$ Although the relative importance of the decline in these different 


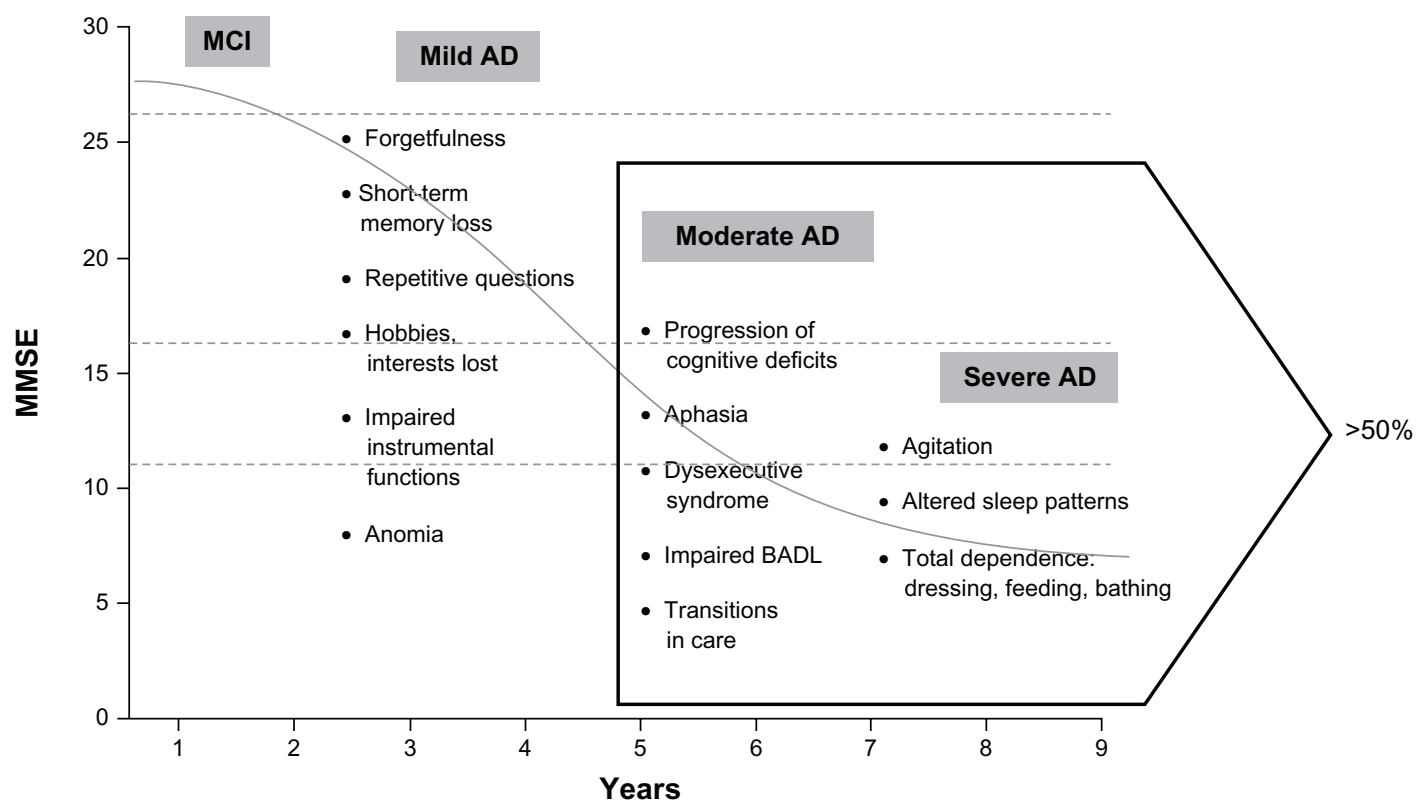

Figure I Symptom progression in Alzheimer's disease.

Note: Modified from Feldman HH, Woodward M. The staging and assessment of moderate to severe Alzheimer's disease. Neurology. 2005;65:SI0-SI7. With permission from Wolters Kluwer Health. ${ }^{4}$

Abbreviations: AD, Alzheimer's disease; MMSE, Mini-Mental State Examination; MCI, mild cognitive impairment; BADL, basic activities of daily living.

cognitive domains remains undefined, worsening language abilities, or aphasia, has been suggested to have more clinical relevance than other domains, such as memory, orientation, and reasoning, in progression from the moderate to severe stages of $\mathrm{AD}$, given that decline in language has been shown to correlate with noncognitive items, such as personal care, hobbies, occupations, and behavior. ${ }^{7}$ Language impairment is a significant issue in most patients as they pass through moderate into severe disease stages. Yet even early on in the disease state, aphasia is an important characteristic; recently published criteria for the clinical diagnosis of $\mathrm{AD}$ include language impairment at onset in one of the subtypes. ${ }^{8}$ Differentiation between AD and other types of dementia, such as primary progressive aphasia, one of the major types of frontotemporal dementia, may be made on the basis of association with causative mutations or different pathologies. However, pathological studies ${ }^{9,10}$ have shown that $22 \%-28 \%$ of cases of primary progressive aphasia are caused by AD.

Herein we discuss the progressive language impairment in patients with $\mathrm{AD}$ and the associated psychosocial burden, and review the published literature on clinical studies of the benefits of acetylcholinesterase inhibitors (AChEIs) in managing language deficits in patients with $\mathrm{AD}$.

\section{Language impairment in AD}

Language impairment in $\mathrm{AD}$ is primarily a result of decline in semantic and pragmatic levels of language processing. ${ }^{11}$
Semantic processing involves language content, such as words and their meaning, and the associated impairments include difficulties with word finding, naming, and word comprehension, as well as semantic paraphasia (choosing incorrect words), empty speech (using ambiguous referents), inventing words, and loss of verbal fluency. ${ }^{11}$ Pragmatic processing goes beyond words and their meaning and concerns language adaptation to the social situation. ${ }^{11}$ Examples of pragmatic problems are speaking too much at inappropriate times, talking too loudly, repeating ideas, and digressing from the topic. Deficits in pragmatic processing may also be influenced by other AD symptoms, such as impairments in memory and concentration, and disinhibition. However, it is thought that semantics and pragmatics are interdependent such that semantic deficits in word finding and naming may contribute to pragmatic problems in maintaining the topic of conversation or may overwhelm the cognitive ability of the patient, resulting in shouting or use of profanity. ${ }^{11,12}$

Although subtle language deficits are detected in the early stages of $\mathrm{AD}$, the mechanics of speech (ie, phonological and syntactic performance) appear to be well preserved, and at least some of the perceived deficits result from dysfunction in nonlinguistic domains such as attention and executive control. ${ }^{13}$ In the early stages of $\mathrm{AD}$, language impairment involves lexical retrieval problems, loss of verbal fluency, and breakdown in comprehension of higher order written and spoken languages. In the moderate and severe stages of $\mathrm{AD}$, 
the loss of verbal fluency is profound, with breakdown of comprehension and literal and semantic paraphrases prominent (Table 1); in very severe $\mathrm{AD}$, speech is often restricted to echolalia and verbal stereotypy.,14

\section{Psychosocial burden of language impairment on patients and caregivers}

During the moderate to severe stages of AD, the patients' language declines and deficits often result in a loss of ability to express their needs, which in turn affects their quality of life, prognosis, and social relationships, and can contribute significantly to patient and caregiver burden. ${ }^{4,15}$ Indeed, with progressive loss of language and other cognitive abilities, these patients lose their autonomy, and quality of life worsens as they become unable to sustain normal daily activities; as has been demonstrated in a study showing that several cognitive abilities, including expressive language, are required to maintain function in activities of daily living. ${ }^{16}$ Emotional distress/depression, severity of language deficit, and communication disability are some predictors of health-related quality of life in patients with language impairments. ${ }^{17}$ To this effect, assessment of healthrelated quality of life in a hospital-based, long-term care patient population showed that language impairments had a stronger association with negative quality of life than did cancer, after controlling for age, gender, and other diagnoses. ${ }^{18}$ In addition to predicting quality of life, severity of language impairment was suggested to be a predictor of mortality, ${ }^{19}$ with verbal frequency being the most significant neuropsychological predictor. ${ }^{20}$

Table I Language impairments in Alzheimer's dementia

\begin{tabular}{|c|c|c|}
\hline & Early stage & Moderate-severe \\
\hline $\begin{array}{l}\text { Spontaneous } \\
\text { speech }\end{array}$ & Fluent, grammatical & $\begin{array}{l}\text { Nonfluent, } \\
\text { echolalic } \\
\text { neologisms }\end{array}$ \\
\hline $\begin{array}{l}\text { Paraphasic } \\
\text { errors }\end{array}$ & Semantic & $\begin{array}{l}\text { Semantic and } \\
\text { phonemic }\end{array}$ \\
\hline Repetition & Intact & Impaired \\
\hline Naming & Impaired (mild) & Impaired \\
\hline $\begin{array}{l}\text { Comprehension } \\
\text { of words }\end{array}$ & Intact & Impaired \\
\hline $\begin{array}{l}\text { Syntactic } \\
\text { comprehension }\end{array}$ & Intact & Impaired \\
\hline Reading & \pm intact & Impaired \\
\hline Writing & \pm intact & Impaired \\
\hline $\begin{array}{l}\text { Word and object } \\
\text { knowledge } \\
\text { (sematic knowledge) }\end{array}$ & $\begin{array}{l}\text { Intact for more } \\
\text { frequently used words } \\
\text { and objects; impaired } \\
\text { for less frequently } \\
\text { used words and objects }\end{array}$ & Impaired \\
\hline
\end{tabular}

Note: Copyright (C) 2008. Reproduced with permission Tang-Wai DF, Graham NL. Assessment of language function in dementia. Geriatr Aging. 2008; I 1:103-1 10.14
An earlier study in elderly patients showed that language impairments were associated with both behavioral and psychological symptoms of dementia. Specifically, impairment of expressive language was associated with delusions and with a tendency for depression. ${ }^{21}$ In addition, studies of the social relationships of stroke patients found that those experiencing language impairments were most likely to find it difficult to maintain existing friendships and often found themselves withdrawing from social contact. ${ }^{22}$ Progressive loss of communication via language has also been shown to trigger other behavioral problems, such as agitation, restlessness, and wandering in patients with dementia. ${ }^{11}$

When loss of memory, loss of judgment, and impaired communication increase the need for supervision and caregiving, a frequent consequence is an increase in caregiver burden. ${ }^{2}$ Approximately $80 \%$ of care is provided by family caregivers, ${ }^{2}$ so it is no surprise that family members who self-report caring for relatives with dementia indicated that communication breakdown often led to decline in the quality of their interaction and relationship. ${ }^{11}$

\section{Measuring language impairment in AD}

Rating scales are essential tools for diagnosis, staging, and monitoring of $\mathrm{AD}$ symptoms in response to therapy. Given that cognition is the primary impairment, most AD assessments have been more focused on rating overall cognitive deficits than on functional or behavioral symptoms. ${ }^{23}$ Because of the centrality of language to cognitive function, languagespecific scales designed to measure progressive language deficits through the course of AD progression have been developed in recent years. ${ }^{14}$

In designing tools to assess language impairment, fluency in spontaneous speech, naming or word-finding, grammar, and paraphasic errors are key aspects of the assessment and are required for diagnosis of the types of dementia. ${ }^{14}$ Formal language assessment involves the following domains: naming (eg, the Boston Naming Test), repetition of words/sentences, comprehension (auditory and semantic knowledge), reading, and writing. ${ }^{14}$ There are a number of disease severityappropriate scales that are currently used in the clinical trial setting to measure changes in cognitive deficits, including language. For mild and moderate AD, the Mini-Mental State Examination (MMSE) and the cognitive subscale of the Alzheimer's Disease Assessment Scale (ADAS-cog) were designed to assess three core symptom domains, ie, memory, language, and praxis. ${ }^{24}$ With high inter-rater and test-retest reliability, the ADAS-cog, consisting of 11 items and three 
domains, is now considered the "gold standard" measure of cognitive performance in mild to moderate $\mathrm{AD}$ in clinical trials. ${ }^{25}$ However, for moderate to severe AD, the MMSE and ADAS-cog scales are considered relatively insensitive for measuring disease progression as a result of floor effects. ${ }^{26}$ It is also noteworthy that neither the MMSE nor the ADAS-cog are specific language assessments and more specific language measures (eg, the Boston Naming Test) may be useful in cases where further evaluation of language is warranted.

In moderate to severe and severe $\mathrm{AD}$, the Severe Impairment Battery (SIB) is used to evaluate the severity of cognitive dysfunction across nine cognitive domains, ie, language, memory, praxis, visuospatial ability, social interaction, attention, orientation, construction, and orienting to name. ${ }^{26-28}$ The sensitivity, reliability, and validity of the SIB are well established, and administration requires about 30 minutes. ${ }^{29}$ Because of the importance of language to cognitive function, 24 of the 51 total items and subitems in the full SIB scale assess language ability and comprise the SIB language subscale. ${ }^{29}$ It is notable that, although the full SIB assesses nine core cognitive domains and the ADAS-cog only three core domains, a larger proportion of the full SIB (47\%, 24 of 51 total items) pertains to evaluation of language function, in contrast with only $28 \%$ of the ADAS-cog scale. ${ }^{30}$ It is possible that the larger proportion of language items in the $\mathrm{SIB}$, combined with the significant language impairment seen among patients at the moderate and severe disease stages, contributes to the additional sensitivity of the SIB in measuring change in cognition in more advanced AD.

In a recent factor analysis, the 24 items in the SIB language subscale were analyzed to identify those most relevant to language function. Using baseline data from four placebocontrolled trials of memantine in moderate to severe AD, 21 of the 24 items were included in the SIB language scale (SIB-L). ${ }^{29}$ Pearson correlation of SIB-L with the full SIB was high $(r=0.943)$, indicating that the SIB-L scale maintains the sensitivity of the complete SIB scale. More recently, a new 21-item SIB-derived language subscale [SIB(lang)] was also constructed by performing a similar factor analysis on the 24 language items using baseline data from a single large randomized trial of donepezil $23 \mathrm{mg}$ /day versus donepezil $10 \mathrm{mg} /$ day in moderate to severe AD. ${ }^{31}$ To assess further the clinical utility of the SIB-derived language scales, SIB-L and SIB(lang) scores were correlated with other severity measures (MMSE, severe version of the Alzheimer's disease Cooperative Study-Activities of Daily Living Inventory [ADCSADL-sev] and the Clinician's Interview-Based Impression of Severity-plus caregiver input/Clinician's Interview-Based
Impression of Change-plus caregiver input [CIBIS-plus/ CIBIC-plus]). ${ }^{31}$ At baseline and at end point, correlations between the SIB-derived language scales and the MMSE were strong, but were weak to moderate with ADCS-ADL-sev and CIBIS-plus; however, correlations between changes in scores on the SIB-derived language scales and changes in scores on the MMSE were relatively weak. Furthermore, correlations between changes in scores on the SIB-derived language scales and baseline ADCS-ADL-sev and CIBIC-plus scores were also weak. These observations suggest that (1) cognition, as measured by the MMSE, is strongly related to language abilities that are measured by SIB-derived language scales, but changes in cognition and changes in language track differently over time, and (2) there is little relationship between baseline functional status and treatment-derived changes in language abilities.

\section{Benefits of AChEI pharmacotherapy on language function}

Currently there are three AChEIs approved by the US Food and Drug Administration (FDA) for the treatment of AD in use in clinical practice. Donepezil, rivastigmine, and galantamine are indicated for the treatment of mild to moderate AD. Donepezil is also approved for the treatment of moderate to severe and severe AD. Although these agents have been approved for more than 10 years, to date, no clinical trial has been performed to evaluate the effects of AChEIs on language specifically, and the focus has been primarily on the overall effects of AChEIs on cognition. However, based on several cognitive domain analyses and the recent development of SIB-derived language scales, it is now possible to review the data for the benefits of AChEIs on language function in patients with AD.

\section{Donepezil}

A number of studies in patients with moderate or severe AD have examined the treatment effect of the $10 \mathrm{mg}$ /day dose of donepezil on individual cognitive domains, including language. Based on an SIB domain analysis using data from a placebo-controlled study in severe $\mathrm{AD}$, patients treated with donepezil $10 \mathrm{mg} /$ day for 6 months showed improvements in eight of nine SIB domains, with a significant difference between donepezil and placebo shown for language (as well as the praxis and visuospatial domains). ${ }^{32}$ In a similar global study of patients with severe AD receiving donepezil $10 \mathrm{mg}$ /day for 6 months, language was again improved from baseline, but declined in the placebo group. ${ }^{33}$ Similar language benefits with donepezil $10 \mathrm{mg} /$ day were reported in 
two analyses using pooled data from studies of patients with moderate to severe or severe $\mathrm{AD}$; in both analyses, language improved from baseline with donepezil and declined with placebo. ${ }^{34,35}$ Consistent with these findings, a recent post hoc analysis reported that, after 6 months' treatment with donepezil $10 \mathrm{mg} /$ day, patients with moderate to severe AD showed less worsening in language compared with those receiving placebo. ${ }^{7}$

Recently, a higher dose of donepezil (23 mg/day) was approved by the FDA for the treatment of moderate to severe $\mathrm{AD}$ based on outcomes from a large multinational, doubleblind trial comparing donepezil $23 \mathrm{mg}$ /day with donepezil $10 \mathrm{mg} /$ day. ${ }^{36}$ To determine whether treatment with this higher dose was associated with specific language benefits in patients with moderate and severe $\mathrm{AD}$, a post hoc analysis was performed using the SIB-L and SIB(lang) scales. ${ }^{31}$ Data from this analysis showed that, after 24 weeks of treatment, donepezil $23 \mathrm{mg}$ /day was associated with improved language function, whereas donepezil $10 \mathrm{mg} /$ day was associated with a decline in language function (Figure 2). ${ }^{31}$ Moreover, the significant language benefits of donepezil $23 \mathrm{mg}$ /day over $10 \mathrm{mg} /$ day were not only evident in the overall study population, but also more prominent in patient subgroups based on more advanced baseline AD (MMSE scores 0-16) and on concomitant use of memantine. ${ }^{31,37}$ In this study, donepezil $23 \mathrm{mg}$ showed a 0.8-point improvement over the lower dose measured using the SIB-L (total score range 0-41). The "realworld" clinical meaningfulness of this 0.8-point benefit on the SIB-L was not assessed. However, it is noteworthy that this is an improvement over an active therapy, not placebo, and based on studies with other AChEIs in moderate and/or severe populations, ${ }^{38-40}$ untreated patients with advanced AD would likely show a decline in SIB-L scores over a similar study period.

The greater effect of donepezil $23 \mathrm{mg} /$ day over donepezil $10 \mathrm{mg} /$ day on language function may be due to higher-dose donepezil facilitating greater acetylcholinesterase inhibition and thereby increasing cholinergic function in regions of the brain controlling speech and language. Another hypothesis is that the observed language benefits could be driven by enhanced effects of the $23 \mathrm{mg} /$ day dose on regions of the brain controlling other cognitive processes, such as attention and memory. It seems logical that attention deficits could substantially influence a patient's language ability as measured by the SIB-L and SIB[lang] scales, and there is clearly some overlap between certain aspects of language impairment, such as difficulties with word finding, and general memory problems. Further prospective studies are needed
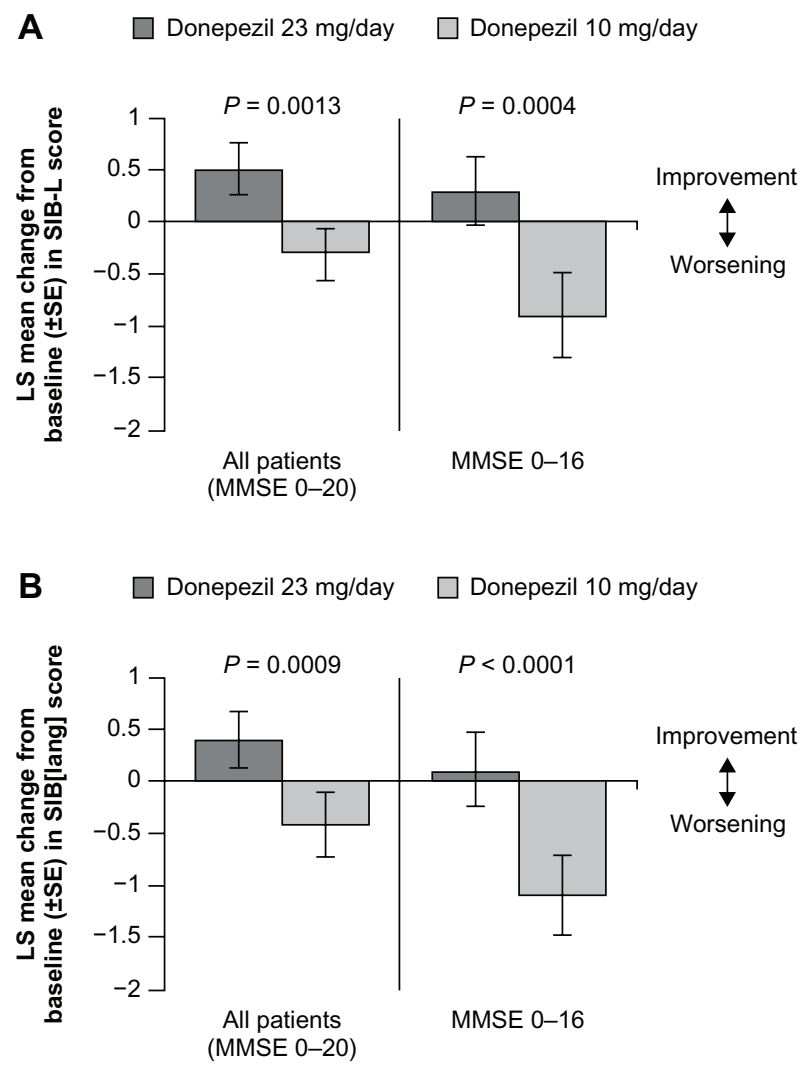

Figure 2 Effect of donepezil $23 \mathrm{mg} /$ day on language function after 24 weeks of treatment in patients with moderate to severe Alzheimer's disease. Mean change in LS from baseline to week 24 in SIB-L scores (A) and 2I-item SIB-derived language subscale scores $(\mathbf{B})$.

Note: C20II Springer. Reproduced with permission from Ferris SH, Schmitt FA, Saxton J, et al. Analyzing the impact of $23 \mathrm{mg} /$ day donepezil on language dysfunction in moderate to severe Alzheimer's disease. Alzheimers Res Ther. 201 I;3(3):22. ${ }^{31}$ Abbreviations: LS, least squares; SIB-L, Severe Impairment Battery language scale; MMSE, Mini-Mental State Examination; SE, standard error of the mean.

to determine the direct and indirect mechanisms whereby donepezil $23 \mathrm{mg}$ /day provides improved language benefits over the donepezil $10 \mathrm{mg} /$ day dose.

\section{Rivastigmine}

Although oral formulations of rivastigmine have been approved for the treatment of mild to moderate AD since 2000 and transdermal formulations since 2007 , data pertaining to the treatment effect on individual cognitive domains are limited. In one retrospective pooled analysis designed to assess the treatment effect of rivastigmine versus placebo on the individual domains of the ADAS-cog in patients with mild to moderate $\mathrm{AD}$, language declined with both rivastigmine doses and with placebo, although the extent of the decline was significantly less with the higher dose rivastigmine capsule versus placebo (Figure 3). ${ }^{39}$ Conversely, in a similar clinical study, treatment with the rivastigmine transdermal patch tended to show 


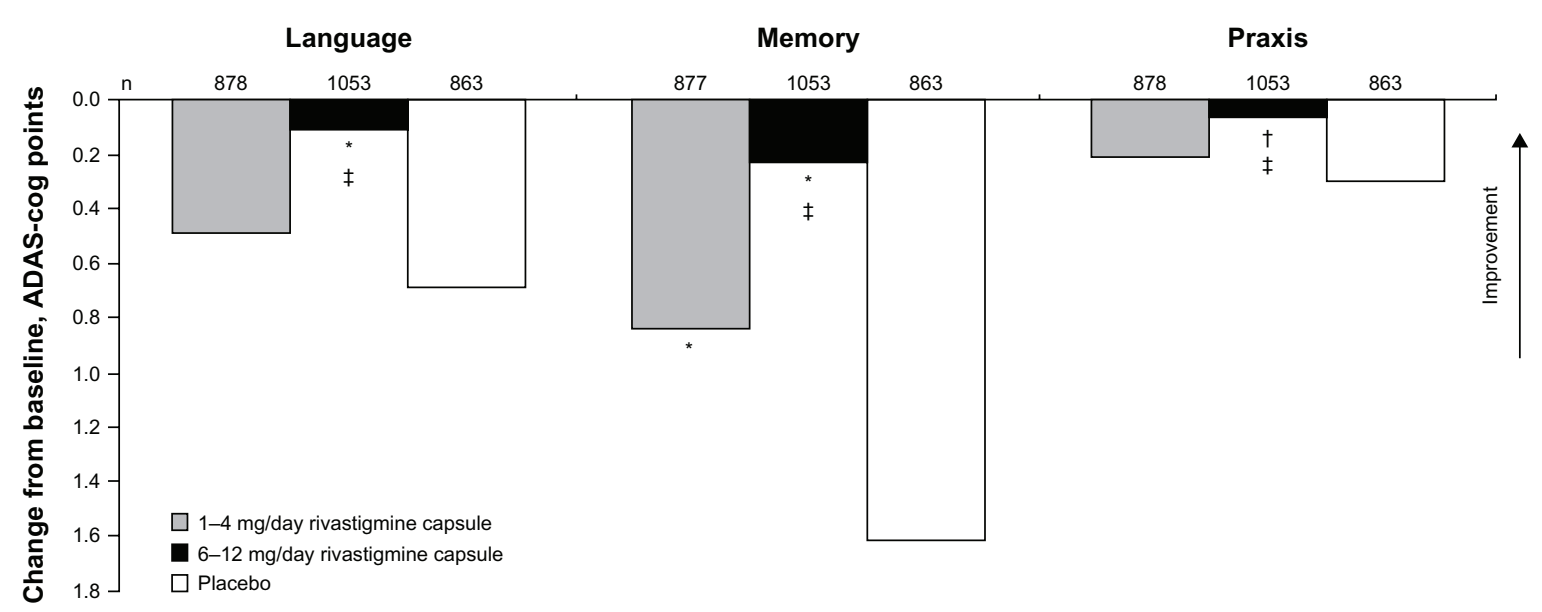

Figure 3 Effect of rivastigmine on language function after 26 weeks of treatment in patients with mild to moderate Alzheimer's disease.

Notes: Mean changes from baseline on ADAS-cog subscale scores at week 26 (intention-to-treat population). $* P<0.000$; ${ }^{\dagger} P<0.00$ I versus placebo; ${ }^{\dagger} P<0.00$ I versus I to $4 \mathrm{mg} /$ day rivastigmine capsule.

Reproduced from Farlow MR, Cummings JL, Olin JT, Meng X. Effects of oral rivastigmine on cognitive domains in mild-to-moderate Alzheimer's disease. Am J Alzheimers Dis Other Demen. 2010;25(4):347-352. With permission from Sage publications. ${ }^{39}$

Abbreviation: ADAS-cog, cognitive subscale of the Alzheimer's Disease Assessment Scale.

language improvements from baseline and a significant benefit over placebo in patients with mild to moderate AD. However, in this study, treatment with the higher-dose rivastigmine capsule did not show significant language benefits over placebo. ${ }^{40}$

\section{Galantamine}

Like rivastigmine, galantamine has been approved for the treatment of mild to moderate $\mathrm{AD}$ for about a decade.
However, data on the effects of this treatment on individual cognitive domains, including language, are lacking. In a single large multinational study designed to assess the effects of treatment with galantamine in patients with severe $A D$, galantamine was associated with improvement on six of the nine SIB domains, with significant benefits over placebo reported for the memory, praxis, and visuospatial domains (Figure 4).$^{38}$ In this study, language improved from baseline

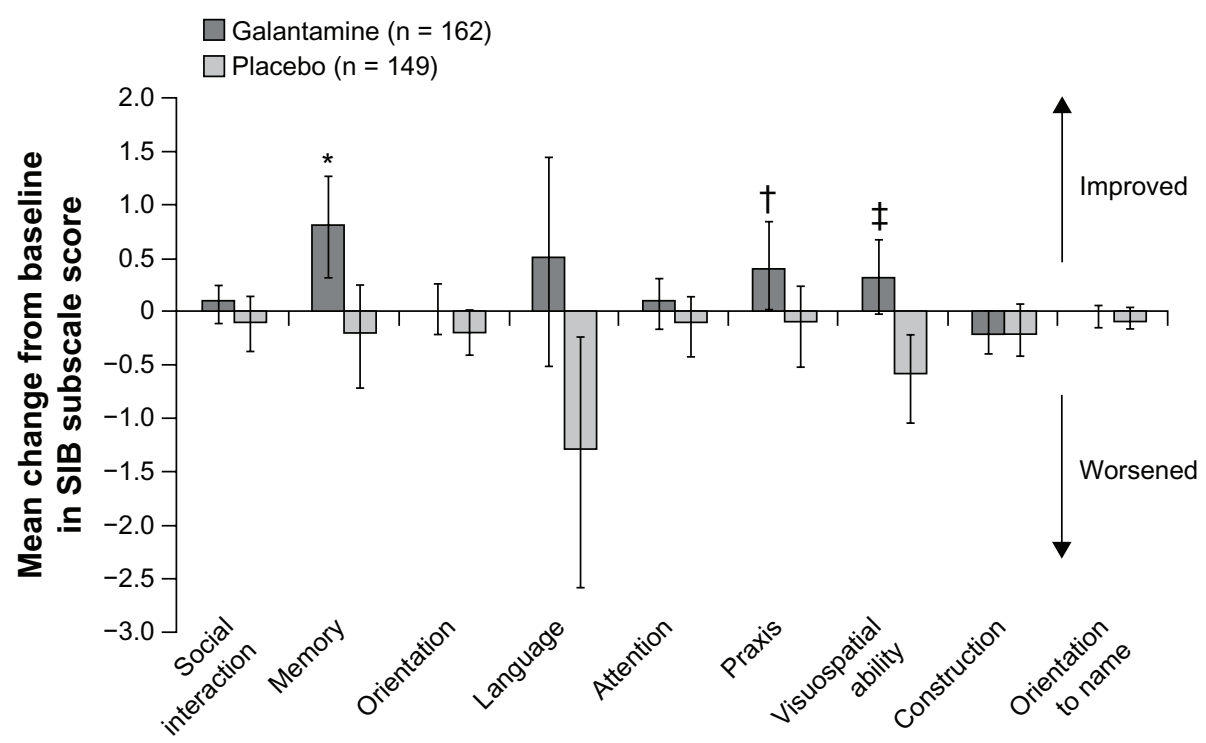

Figure 4 Effect of galantamine on language function after 26 weeks of treatment in patients with severe Alzheimer's disease.

Notes: Change from baseline in SIB subscale scores at week 26 in intention-to-treat population. Bars indicate $95 \%$ confidence interval for comparison with baseline. $* P=0.006 ;{ }^{\dagger} P=0.010 ; \neq P=0.002$ versus placebo.

Reproduced from Burns A, Bernabei R, Bullock R, et al. Safety and efficacy of galantamine (Reminyl) in severe Alzheimer's disease (the SERAD study): a randomised, placebocontrolled, double-blind trial. Lancet Neurol. 2009;8(I):39-47. With permission from Elsevier Ltd. ${ }^{38}$

Abbreviation: SIB, Severe Impairment Battery. 
with galantamine, but declined with placebo; however, the difference between the effects of galantamine and placebo on language function was not statistically significant.

\section{Conclusion}

Language impairment is one of the primary components of cognitive decline in $\mathrm{AD}$ and contributes significantly to reduced quality of life for patients and to caregiver burden. Although clinical trials of AChEIs in patients with AD have traditionally focused on benefits on the core symptoms of cognition, functional activity, and behavior, there are clinical data available, predominantly from post hoc subanalyses, demonstrating that AChEIs can provide language benefits in patients with AD. Prospective studies, ideally using specific language measures, will be necessary to define clearly the benefits of AChEIs on language in patients with $\mathrm{AD}$. However, the existing exploratory data indicate that language benefits associated with AChEIs may be apparent even in the more advanced stages of disease, when preservation or improvement of language function is particularly important, both for the patients and their caregiving network.

\section{Acknowledgments}

Editorial support in the development of this manuscript was provided by R Daniel and K Ayling-Rouse of Parexel, and was funded by Eisai Inc and Pfizer Inc.

\section{Disclosure}

SHF has served as a paid scientific consultant to Accera, Baxter, Bristol-Myers Squibb, Eisai, Elan, Eli Lilly, Janssen AI, MedAvante, Merck, Merz, Neuronix, Novartis, Otsuka, Pfizer, Toyama, and United BioSource. His institution has received grant/contract support for clinical trials from Baxter, Bristol-Myers Squibb, Eisai, Eli Lilly, Janssen AI, Merck, Neuronix, Pfizer, Roche, and Takeda. He also has stock options from Accera, Intellect Neurosciences, MedAvante and Raptor, and owns stock in Lexicon.

MF has served as a paid consultant for Accera, Alltech, Astellas, Bayer, Bristol-Myers Squibb, Eisai Medical Research, GE Healthcare, Helicon, MedAvante, Mediation, Inc., Merck and Co, Inc., Novartis Pharma, Pfizer, Prana Biotech, QR Pharma, Sanofi-aventis Groupe, ScheringPlough, Lilly, Shire Pharmaceuticals, and Toyama, is a paid speaker for Eisai, Forest, Novartis, and Pfizer, and receives research support from Eisai, Eli Lilly and Co, Genentech, Novartis Pharm, and Roche.

\section{References}

1. Alzheimer's Disease International. World Alzheimer Report 2010: The global economic impact of dementia. Alzheimer's Disease International website. Available from: http:/www.alz.co.uk/research/files/ WorldAlzheimerReport2010.pdf. Accessed May 10, 2012.

2. Alzheimer's Association. 2012 Alzheimer's Disease Facts and Figures. Alzheimer's and Dementia. Available from: http://www.alz.org/ downloads/Facts_Figures_2012.pdf. Accessed May 10, 2012.

3. Hebert LE, Scherr PA, Bienias JL, Bennett DA, Evans DA. Alzheimer disease in the US population: prevalence estimates using the 2000 census. Arch Neurol. 2003;60(8):1119-1122.

4. Feldman HH, Woodward M. The staging and assessment of moderate to severe Alzheimer disease. Neurology. 2005;65:S10-S17.

5. Gelb DJ. Measurement of progression in Alzheimer's disease: a clinician's perspective. Stat Med. 2000;19(11-12):1393-1400.

6. Vestal L, Smith-Olinde L, Hicks G, Hutton T, Hart J Jr. Efficacy of language assessment in Alzheimer's disease: comparing in-person examination and telemedicine. Clin Interv Aging. 2006;1(4):467-471.

7. Schwam E, Xu Y. Cognition and function in Alzheimer's disease: identifying the transitions from moderate to severe disease. Dement Geriatr Cogn Disord. 2010;29(4):309-316.

8. McKhann GM, Knopman DS, Chertkow H, et al. The diagnosis of dementia due to Alzheimer's disease: recommendations from the National Institute on Aging-Alzheimer's Association workgroups on diagnostic guidelines for Alzheimer's disease. Alzheimers Dement. 2011;7(3): 263-269.

9. Mesulam M, Wicklund A, Johnson N, et al. Alzheimer and frontotemporal pathology in subsets of primary progressive aphasia. Ann Neurol. 2008;63(6):709-719.

10. Rohrer JD, Rossor MN, Warren JD. Alzheimer's pathology in primary progressive aphasia. Neurobiol Aging. 2012;33(4):744-752.

11. Savundranayagam MY, Hummert ML, Montgomery RJ. Investigating the effects of communication problems on caregiver burden. J Gerontol B Psychol Sci Soc Sci. 2005;60(1):S48-S55.

12. Ripich DN. Functional communication with AD patients: a caregiver training program. Alzheimer Dis Assoc Disord. 1994;8 Suppl 3: 95-109.

13. Manenti R, Repetto C, Bentrovato S, Marcone A, Bates E, Cappa SF. The effects of ageing and Alzheimer's disease on semantic and gender priming. Brain. 2004;127(Pt 10):2299-2306.

14. Tang-Wai DF, Graham NL. Assessment of language function in dementia. Geriatr Aging. 2008;11:103-110.

15. Arrighi HM, Neumann PJ, Lieberburg IM, Townsend RJ. Lethality of Alzheimer disease and its impact on nursing home placement. Alzheimer Dis Assoc Disord. 2010;24(1):90-95.

16. Galasko D, Schmitt F, Thomas R, Jin S, Bennett D. Detailed assessment of activities of daily living in moderate to severe Alzheimer's disease. J Int Neuropsychol Soc. 2005;11(4):446-453.

17. Hilari K, Needle JJ, Harrison KL. What are the important factors in health-related quality of life for people with aphasia? A systematic review. Arch Phys Med Rehabil. 2012;93(Suppl 1):S86-S95.

18. Lam JM, Wodchis WP. The relationship of 60 disease diagnoses and 15 conditions to preference-based health-related quality of life in Ontario hospital-based long-term care residents. Med Care. 2010;48(4): 380-387.

19. Bracco L, Gallato R, Grigoletto F, et al. Factors affecting course and survival in Alzheimer's disease. A 9-year longitudinal study. Arch Neurol. 1994;51(12):1213-1219.

20. Cosentino S, Scarmeas N, Albert SM, Stern Y. Verbal fluency predicts mortality in Alzheimer disease. Cogn Behav Neurol. 2006;19(3): 123-129.

21. Potkins D, Myint P, Bannister C, et al. Language impairment in dementia: impact on symptoms and care needs in residential homes. Int J Geriatr Psychiatry. 2003;18(11):1002-1006.

22. Northcott S, Hilari K. Why do people lose their friends after a stroke? Int J Lang Commun Disord. 2011;46(5):524-534. 
23. Robert P, Ferris S, Gauthier S, Ihl R, Winblad B, Tennigkeit F. Review of Alzheimer's disease scales: is there a need for a new multi-domain scale for therapy evaluation in medical practice? Alzheimers Res Ther. 2010;2(4):24.

24. Rosen WG, Mohs RC, Davis KL. A new rating scale for Alzheimer's disease. Am J Psychiatry. 1984;141(11):1356-1364.

25. Winblad B, Engedal K, Soininen H, et al. A 1-year, randomized, placebocontrolled study of donepezil in patients with mild to moderate AD. Neurology. 2001;57(3):489-495.

26. Schmitt FA, Cragar D, Ashford JW, et al. Measuring cognition in advanced Alzheimer's disease for clinical trials. J Neural Transm Suppl. 2002;62:135-148

27. Emre M, Mecocci P, Stender K. Pooled analyses on cognitive effects of memantine in patients with moderate to severe Alzheimer's disease. J Alzheimers Dis. 2008;14(2):193-199.

28. Schmitt FA, Ashford W, Ernesto C, et al. The severe impairment battery: concurrent validity and the assessment of longitudinal change in Alzheimer's disease. The Alzheimer's Disease Cooperative Study. Alzheimer Dis Assoc Disord. 1997;11 Suppl 2:S51-S56.

29. Ferris S, Ihl R, Robert P, et al. Severe Impairment Battery Language scale: a language-assessment tool for Alzheimer's disease patients. Alzheimers Dement. 2009;5(5):375-379.

30. Schultz RR, Siviero MO, Bertolucci PHF. The cognitive subscale of the "Alzheimer's Disease Assessment Scale" in a Brazilian sample. Braz J Med Biol Res. 2001;34:1295-1302.

31. Ferris SH, Schmitt FA, Saxton J, et al. Analyzing the impact of $23 \mathrm{mg} /$ day donepezil on language dysfunction in moderate to severe Alzheimer's disease. Alzheimers Res Ther. 2011;3(3):22.

32. Winblad B, Kilander L, Eriksson S, et al. Donepezil in patients with severe Alzheimer's disease: double-blind, parallel-group, placebocontrolled study. Lancet. 2006;367(9516):1057-1065.
33. Black SE, Doody R, Li H, et al. Donepezil preserves cognition and global function in patients with severe Alzheimer disease. Neurology. 2007;69(5):459-469.

34. Cummings J, Jones R, Wilkinson D, et al. Effect of donepezil on cognition in severe Alzheimer's disease: a pooled data analysis. J Alzheimers Dis. 2010;21(3):843-851.

35. Winblad B, Black SE, Homma A, et al. Donepezil treatment in severe Alzheimer's disease: a pooled analysis of three clinical trials. Curr Med Res Opin. 2009;25(11):2577-2587.

36. Farlow MR, Salloway S, Tariot PN, et al. Effectiveness and tolerability of high-dose $(23 \mathrm{mg} / \mathrm{d})$ versus standard-dose $(10 \mathrm{mg} / \mathrm{d})$ donepezil in moderate to severe Alzheimer's disease: a 24-week, randomized, double-blind study. Clin Ther. 2010;32(7):1234-1251.

37. Schmitt FA, Ferris SH, Mackell J, Richardson S, Sun Y. Donepezil $23 \mathrm{mg} / \mathrm{d}$ improves cognitive abilities in patients with moderate to severe Alzheimer's disease: evaluating the impact on language. Presented at the 63rd Annual Meeting of the American Academy of Neurology, Honolulu, HI, April 9-16, 2011.

38. Burns A, Bernabei R, Bullock R, et al. Safety and efficacy of galantamine (Reminyl) in severe Alzheimer's disease (the SERAD study): a randomised, placebo-controlled, double-blind trial. Lancet Neurol. 2009;8(1):39-47.

39. Farlow MR, Cummings JL, Olin JT, Meng X. Effects of oral rivastigmine on cognitive domains in mild-to-moderate Alzheimer's disease. Am J Alzheimers Dis Other Demen. 2010;25(4):347-352.

40. Grossberg GT, Schmitt FA, Meng X, Tekin S, Olin J. Reviews: effects of transdermal rivastigmine on ADAS-cog items in mild-tomoderate Alzheimer's disease. Am J Alzheimers Dis Other Demen. 2010;25(8):627-633.
Clinical Interventions in Aging

\section{Publish your work in this journal}

Clinical Interventions in Aging is an international, peer-reviewed journal focusing on evidence-based reports on the value or lack thereof of treatments intended to prevent or delay the onset of maladaptive correlates of aging in human beings. This journal is indexed on PubMed Central, MedLine, the American Chemical Society's 'Chemical Abstracts Ser-

\section{Dovepress}

vice' (CAS), Scopus and the Elsevier Bibliographic databases. The manuscript management system is completely online and includes a very quick and fair peer-review system, which is all easy to use. Visit $\mathrm{http}: / /$ www.dovepress.com/testimonials.php to read real quotes from published authors. 